\title{
Completeness of T, N, M and stage grouping for all cancers in the Mallorca Cancer Registry
}

\author{
M. Ramos ${ }^{1 *}$, P. Franch ${ }^{1}$, M. Zaforteza ${ }^{1,2}$, J. Artero ${ }^{3}$ and M. Durán ${ }^{1}$
}

\begin{abstract}
Background: TNM staging of cancer is used to establish the treatment and prognosis for cancer patients, and also allows the assessment of screening programmes and hospital performance. Collection of staging data is becoming a cornerstone for cancer registries. The objective of the study was to assess the completeness of T, N, M and stage grouping registration for all cancers in the Mallorca Cancer Registry in 2006-2008 and to explore differences in T, N, $\mathrm{M}$ and stage grouping completeness by site, gender, age and type of hospital.

Methods: All invasive cancer cases during the period 2006-2008 were selected. DCO, as well as children's cancers, CNS, unknown primary tumours and some haematological cases were excluded. T, N, M and stage grouping were collected separately and followed UICC (International Union Against Cancer) 7th edition guidelines. For T and N, we registered whether they were pathological or clinical.

Results: Ten thousand two hundred fifty-seven cases were registered. After exclusions, the study was performed with 9283 cases; $39.4 \%$ of whom were women and $60.6 \%$ were men. T was obtained in $48.6 \%$ cases, N in $36.5 \%$, $\mathrm{M}$ in $40 \%$ and stage in $37.9 \%$. T and $\mathrm{N}$ were pathological in $71 \%$ of cases. Stage completeness exceeded $50 \%$ in lung, colon, ovary and oesophagus, although $\mathrm{T}$ also exceeded $50 \%$ at other sites, including rectum, larynx, colon, breast, bladder and melanoma. No differences were found in TNM or stage completeness by gender. Completeness was lower in younger and older patients, and in cases diagnosed in private clinics.
\end{abstract}

Conclusions: T, N, M and stage grouping data collection in population-based cancer registries is feasible and desirable.

Keywords: Cancer registry, Cancer staging, TNM, Completeness, Mediterranean Islands

\section{Background}

The Tumour Node Metastasis (TNM) system is the most extended scheme of stage grouping in cancer [1], although there are still some cancers that cannot be classified within TNM system, such as children's cancers, Central Nervous System (CNS) tumours and some haematological diseases. In others, lymphoma or myeloma for instance, stage grouping can be assessed but not T, N and $\mathrm{M}$.

Stage grouping summarises the anatomical extension of a cancer at the moment of diagnosis and is based on three components: the $\mathrm{T}$ (primary tumour growth), the $\mathrm{N}$ (local

\footnotetext{
*Correspondence: mramos@dgsanita.caib.es

${ }^{1}$ Mallorca Cancer Registry, Public Health Department, Hospital Psiquiàtric 40, 07110 Palma, Balearic Islands, Spain

Full list of author information is available at the end of the article
}

lymph node involvement) and the $\mathrm{M}$ (distant metastasis). Stage grouping classifies cancers into: stage I (small or superficial localised cancer), stage II (large or deep localised cancer), stage III (regionally spread cancer) and stage IV (cancer with distant metastasis). In clinical practice, it is used to establish the treatment as well as the prognosis of each patient so it is important for both hospital clinicians and primary health care physicians. For populationbased cancer registries, stage is becoming a cornerstone because it permits calculation of survival, assessment of the results of screening programmes and inter-hospital performance comparisons. However, only about $23 \%$ of the cancer registries which contributed to the IX volume of Cancer Incidence in Five Continents, recorded stage grouping for all cancer topographies $[2,3]$. The 
Danish Cancer Registry (DCR), the oldest in the world, is one of them [4].

The Mallorca Cancer Registry (MCR) covers the Spanish island of Mallorca, with around 800,000 inhabitants. It was created in 1989 by a group of clinicians, the so-called Grup d'Estudis del Càncer Colorectal. Not until 2008 was it integrated into the Public Health Department. MCR had started the registration of T, N and $\mathrm{M}$ and stage tentatively in 2000 . Since 2006, it has become standard procedure for all cancer sites.

The objectives of this study are: 1) To assess the completeness of $\mathrm{T}, \mathrm{N}$ and $\mathrm{M}$ and stage registration for all cancers in the MCR between 2006 and 2008, and 2) To explore differences in completeness by site, gender, age and type of hospital. Both objectives pursue the improvement the collection of $\mathrm{T}, \mathrm{N}, \mathrm{M}$ and stage grouping in the MCR, as well as its accuracy.

\section{Methods}

MCR collects all invasive and in situ cancer cases at all topographies, plus uncertain and benign bladder and CNS tumour cases. Since 2000, registration of skin cancer cases other than melanoma, mainly squamous and basal cell carcinoma has been suspended because of the enormous workload it generates (around $40 \%$ of all cancers).

\section{Dataset}

All invasive cancer cases diagnosed in the period 2006 to 2008 were selected. Death Certificate Only (DCO) cases (cases identified only through the death certificate) as well as children's cancers (0-14 years inclusive), CNS, unknown primary tumours (C26, C39, C48, C76 and C80) and some haematological cases (leukaemia and immunoproliferative, myeloproliferative and myelodysplastic syndromes) were excluded because they cannot be staged.

We included the following variables: gender; date of birth; type of hospital where the case was diagnosed (public versus private); date of diagnosis; topography and morphology according the International Classification of Diseases for Oncology (ICD-O) 3rd edition [5]; T, N, M and stage grouping according to guidelines in the Union for International Cancer Control (UICC) 7th edition [1]. We clustered some topographies and we identified some cancers through morphology (Table 1).

$\mathrm{T}, \mathrm{N}, \mathrm{M}$ and stage grouping data were collected by two doctors and two nurses specifically trained from distinct sources: pathology reports; diagnostic imaging test reports such as computerised axial tomography or echoendoscopy, and clinical records. Initially, we registered the information available in these reports, recording $\mathrm{T}$, $\mathrm{N}, \mathrm{M}$ and stage grouping separately. Nevertheless, when
Table 1 ICD-O 3rd edition grouping used

\begin{tabular}{|c|c|}
\hline Topographies & Cancers \\
\hline $\mathrm{COO-C14}$ & Head and neck \\
\hline $\mathrm{C} 15$ & Oesophagus \\
\hline $\mathrm{C} 16$ & Stomach \\
\hline $\mathrm{C} 17$ & Small intestine \\
\hline $\mathrm{C} 18$ & Colon \\
\hline C19-C21 & Rectum \\
\hline C22.0 & Liver \\
\hline $\mathrm{C} 22.1, \mathrm{C} 24$ & Biliary tract \\
\hline $\mathrm{C} 23$ & Gallbladder \\
\hline $\mathrm{C} 25$ & Pancreas \\
\hline C 30, C31 & Nasal cavity and sinuses \\
\hline $\mathrm{C} 32$ & Larynx \\
\hline C34 & Lung \\
\hline C 33, C 37, C38 & Other thoracic organs \\
\hline $\mathrm{C} 40, \mathrm{C} 41$ & Bone \\
\hline $\mathrm{C} 47, \mathrm{C} 48$ & Soft tissues \\
\hline $\mathrm{C} 50$ & Breast \\
\hline C51 & Vulva \\
\hline C52 & Vagina \\
\hline C53 & Cervix uteri \\
\hline C54, C55 & Uterus \\
\hline C56 & Ovary \\
\hline C57 & Other female genital organs \\
\hline $\mathrm{C} 60$ & Penis \\
\hline C61 & Prostate \\
\hline C62 & Testis \\
\hline C63 & Other male genital organs \\
\hline C64 & Kidney \\
\hline C65-C68 & Bladder and urinary tract \\
\hline C69 & Eye \\
\hline $\mathrm{C} 73$ & Thyroid gland \\
\hline $\mathrm{C} 74$ & Adrenal gland \\
\hline Morphologies & Cancers \\
\hline $8720-8790$ & Melanoma \\
\hline $9590-9729$ & Lymphoma \\
\hline $9731-9734$ & Myeloma \\
\hline
\end{tabular}

they were not available, but we could calculate it, we did. Indeed, for $\mathrm{T}$ and $\mathrm{N}$ components, we registered whether they were pathological (from pathology reports) or clinical (from radiology reports) according to UICC 7th edition rules [1]. For some gynaecological tumours, especially ovary and cervix, information on the stage grouping was available, but not the $\mathrm{T}, \mathrm{N}$ and $\mathrm{M}$ components. Indeed, when $\mathrm{M}$ was 1 , we assumed stage IV even in the absence of the $\mathrm{T}$ and $\mathrm{N}$. 


\section{Statistical analysis}

A descriptive stratified analysis was performed using proportions and their confidence intervals at $95 \%$ of $\mathrm{T}, \mathrm{N}, \mathrm{M}$ and stage grouping by topography or histology, gender, age and type of hospital. The SPSS 19th edition software package was used for statistical analysis.

This study is part of the quality assessments performed regularly in the MCR, so it has not been presented to any Ethical Committee. According to the Law 5/2003 of Health of the Balearic Islands and the Decree 6/2013 establishing the competency and organic structure of the Balearic Government, the Public Health Department has the competency to create and manage disease registries. MCR send regularly their data to the International Agency of Clinical Research (IACR) and to the European Network of Cancer Registries (ENCR). These data, in aggregate format, are openly available.

\section{Results}

During the period 2006-2008, 10,257 cases of invasive cancer were registered in the MCR, of which 167 cases were excluded because they were DCO, 61 as they were in children, 165 because they were CNS, 221 cases due to unknown primary tumour and 427 as they were leukaemia or other haematological syndromes. Finally, the study was performed with 9283 cases.

In men, prostate cancer was the most frequent with $24.6 \%$ of cases, followed by lung (20.9 \%), bladder (11.3\%), and colon (10.2\%). In women, breast cancer was by far the most frequent with $34.2 \%$ of cases, followed by colon (11.5\%), uterus (7.3\%) and lung (6.7 \%) (Table 2).

Distribution of cases by gender was as follows: $39.4 \%$ in women and $60.6 \%$ in men. Regarding age at diagnosis: $4.8 \%$ were under 40 years old, $42.3 \%$ were between 41 and $65,38.7 \%$ between 66 and 80 and $14.2 \%$ older than 80. Three out of four patients $(74.2 \%)$ were treated at public hospitals, and the rest (25.8 \%) at private clinics.

Stage grouping data was obtained in 3514 cases (37.9 \%), $\mathrm{T}$ in 4508 cases (48.6 \%), $\mathrm{N}$ in 3392 (36.5\%) and $\mathrm{M}$ in 3769 (40.6\%). $\mathrm{T}$ and $\mathrm{N}$ components were pathological in $70.6 \%$ and $70.9 \%$ of cases respectively. Distribution of T, N, M and stage grouping completeness by topography or histology is shown in Table 1 . Stage grouping completeness exceeded $50 \%$ in lung, colon, ovary and oesophagus; $\mathrm{T}$ completeness exceeded $50 \%$ in colon, rectum, larynx, breast, penis, testis, bladder and urinary tract and melanoma; $\mathrm{N}$ completeness exceeded 50 \% in colon, rectum and breast; and finally, $\mathrm{M}$ completeness exceeded $50 \%$ in oesophagus, colon, rectum, lung and melanoma. $\mathrm{T}$ and $\mathrm{N}$ were mostly pathological in colon, gallbladder, larynx, breast, vulva, cervix uteri, uterus, ovary, penis, prostate, kidney and thyroid gland, and mostly clinical in stomach, pancreas, lung and bladder and urinary tract. In some cases, such as the ovary,
$\mathrm{T}$ and $\mathrm{N}$ were recorded in less than $20 \%$ of cases, although stage grouping was registered in more than half.

Distribution of T, N, M and stage grouping completeness by gender, age and type of hospital can be seen in Table 3. Differences by age and type of hospital were observed, but not by gender.

\section{Discussion}

We hope that this paper will be of interest not only to cancer-registry staff, but also to hospital clinicians and primary health care physicians, as they would benefit most from an optimal registration of T, N, M and stage grouping, and are well placed to contribute to building a comprehensive population-based cancer register.

We obtained stage grouping data in almost one in two cases. It is clear that this percentage is not high enough. But looking through the results, we realise that we have been too conservative in $\mathrm{N}$ and $\mathrm{M}$ assignment. First, according to the 7th edition of the IUCC TNM guide [1], the use of $X$ for the $M$ category is considered to be inappropriate as clinical assessment of metastasis can be based on physical examination alone. Following this rule, the percentage of $\mathrm{M}$ obtained in our series should be $100 \%$ rather than $40 \%$, so we could assume the remaining $60 \%$ to be M0, especially if the patient is alive. Furthermore, in daily practice, oncologists and other clinicians make assumptions to complete the TNM components and make treatment decisions. Cancer registries could do the same, taking advantage of the fact that $\mathrm{T}, \mathrm{N}, \mathrm{M}$ and stage data are collected retrospectively. For instance, looking at our data for bladder and urinary tract cancer, we only obtained $5.9 \%$ of stage grouping, but $77.7 \%$ of the $\mathrm{T}$ component, while in the DCR they obtained $44.1 \%$ of stage grouping, but only $61.8 \%$ of $\mathrm{T}$ [6]. We believe that it could be assumed that all T1 cases are stage 1, even if the $\mathrm{N}$ component has not been verified, especially if they are asymptomatic and alive 5 years after the diagnosis.

To reduce the percentage of missing values, an alternative is to use the Summary Stage 2000 proposed by the American Surveillance, Epidemiology and End Results Program (SEER), a simplified scheme of staging grouping in: in situ, localised, locally extended and disseminated cancers, as the DCR did, assuming a relatively small loss of information compared to the stage grouping [7-10]. In our opinion, it is better to keep using T, $\mathrm{N}, \mathrm{M}$ and stage grouping, trying to reduce the percentage of unknown stage cases and using multiple imputation method to deal with missing values, as they have shown to provide accurate estimates [11, 12].

Completeness of $\mathrm{T}, \mathrm{N}, \mathrm{M}$ and stage grouping was similar in men and women. Regarding age, we did not observe a decline with age as seen in the DCR or the 
Table 2 Completeness of TNM \& stage registration in the Mallorca Cancer Registry (2006-2008)

\begin{tabular}{|c|c|c|c|c|c|c|c|c|c|c|c|}
\hline \multirow[t]{2}{*}{ Cancers } & \multirow{2}{*}{$\begin{array}{l}\text { Number } \\
\text { cases }\end{array}$} & \multicolumn{3}{|l|}{$T$} & \multicolumn{3}{|l|}{$\mathrm{N}$} & \multicolumn{2}{|l|}{$M$} & \multicolumn{2}{|c|}{ Stage } \\
\hline & & $\%$ & $\mathrm{C} 195 \%$ & $\% p^{a}$ & $\%$ & $\mathrm{C} 195 \%$ & $\% p^{a}$ & $\%$ & $\mathrm{C} 195 \%$ & $\%$ & $\mathrm{Cl} 95 \%$ \\
\hline Head and neck & 359 & 42.3 & $37.3-47.5$ & 65.8 & 41.2 & $36.2-46.4$ & 62.1 & 32.9 & $28.2-37.9$ & 25.1 & $20.9-29.8$ \\
\hline Oesophagus & 103 & 44.7 & $35.4-54.3$ & 23.9 & 50.5 & $41.0-59.9$ & 19.2 & 54.4 & $44.8-63.7$ & 53.4 & $43.8-62.7$ \\
\hline Stomach & 265 & 43.0 & $37.2-49.0$ & 70.2 & 42.3 & $36.5-48.3$ & 70.5 & 46.8 & $40.9-52.8$ & 50.2 & $44.2-56.2$ \\
\hline Small intestine & 34 & 20.6 & $10.3-36.8$ & 100.0 & 20.6 & $10.6-36.8$ & 100.0 & 32.4 & $19.1-49.2$ & 32.4 & $19.1-49.2$ \\
\hline Colon & 926 & 79.2 & $76.4-81.6$ & 96.6 & 77.9 & $75.1-80.4$ & 96.5 & 63.5 & $60.3-66.5$ & 66.0 & $62.9-69.0$ \\
\hline Rectum & 493 & 72.8 & $68.7-76.5$ & 68.8 & 70.4 & $66.2-74.2$ & 68.9 & 61.9 & $57.5-66.0$ & 50.3 & $45.9-54.7$ \\
\hline Liver & 217 & 1.8 & $0.7-4.6$ & 100.0 & 0.0 & $0.0-1.7$ & 0.0 & 5.5 & $3.2-9.4$ & 6.0 & $3.5-10.0$ \\
\hline Biliary tract & 104 & 20.2 & $13.6-28.9$ & 90.5 & 18.3 & $12.2-26.8$ & 89.5 & 22.1 & $15.2-31.0$ & 19.2 & $12.8-27.8$ \\
\hline Gallbladder & 52 & 30.8 & $19.9-44.3$ & 93.7 & 23.1 & $13.7-36.1$ & 83.3 & 38.5 & $26.5-52.0$ & 26.9 & $23.1-48.2$ \\
\hline Pancreas & 224 & 23.2 & $18.2-29.2$ & 26.9 & 22.8 & $17.8-28.7$ & 29.4 & 47.8 & $41.3-54.3$ & 48.7 & $42.2-55.2$ \\
\hline Nasal cavity and sinuses & 12 & 8.3 & $1.5-35.4$ & 0.0 & 8.3 & $1.5-35.4$ & 0.0 & 8.3 & $1.5-35.4$ & 0.0 & $0.0-24.2$ \\
\hline Larynx & 168 & 54.2 & $46.6-61.5$ & 81.3 & 50.0 & $42.5-57.5$ & 71.4 & 43.5 & $36.2-51.0$ & 38.1 & $31.1-45.6$ \\
\hline Lung & 1303 & 43.3 & $40.6-46.0$ & 21.6 & 43.6 & $40.9-46.3$ & 21.6 & 66.9 & $64.3-69.4$ & 67.5 & $64.9-69.9$ \\
\hline Other thoracic organs & 34 & 20.6 & $10.3-36.8$ & 57.1 & 14.7 & $6.4-30.1$ & 40.0 & 23.5 & $12.4-40.0$ & 23.5 & $12.4-40.0$ \\
\hline Bone & 33 & 12.2 & $4.8-27.3$ & 75.0 & 12.1 & $4.8-27.3$ & 75.0 & 21.2 & $10.7-37.7$ & 6.1 & $1.7-19.6$ \\
\hline Soft tissues & 63 & 19.0 & $11.2-30.4$ & 83.3 & 15.9 & $8.9-26.8$ & 70.0 & 22.2 & $13.7-33.9$ & 14.3 & $7.7-25.0$ \\
\hline Breast & 1169 & 65.3 & $62.5-67.9$ & 87.7 & 60.7 & $57.8-63.4$ & 86.9 & 48.7 & $45.8-51.5$ & 44.4 & $41.6-47.3$ \\
\hline Vulva & 41 & 29.3 & $17.6-44.5$ & 91.7 & 24.4 & $13.8-39.3$ & 80.0 & 26.8 & $15.7-41.9$ & 9.8 & $3.9-22.5$ \\
\hline Vagina & 7 & 0.0 & $0.0-35.4$ & 0.0 & 14.3 & $2.6-51.3$ & 0.0 & 0.0 & $0.0-35.4$ & 14.3 & $2.6-51.3$ \\
\hline Cervix uteri & 141 & 35.5 & $28.0-43.6$ & 80.0 & 28.4 & $21.6-36.3$ & 82.5 & 24.8 & $18.4-32.6$ & 41.1 & $33.3-49.4$ \\
\hline Uterus & 245 & 49.8 & $43.6-56.0$ & 99.2 & 34.7 & $29.0-40.8$ & 94.1 & 37.1 & $31.3-43.3$ & 32.7 & $27.1-38.7$ \\
\hline Ovary & 162 & 17.3 & $12.2-23.8$ & 96.4 & 9.9 & $6.2-15.4$ & 93.7 & 22.8 & $17.0-29.9$ & 53.1 & $45.4-60.6$ \\
\hline Other female genital organs & 6 & 16.7 & $3.0-56.3$ & 100.0 & 16.7 & $3.0-56.3$ & 100.0 & 0.0 & $0.0-39.0$ & 0.0 & $0.0-39.0$ \\
\hline Penis & 28 & 53.6 & $35.8-70.5$ & 93.3 & 17.9 & 7.9-35.6 & 40.0 & 28.6 & $15.2-47.1$ & 14.3 & $5.7-31.5$ \\
\hline Prostate & 1294 & 34.0 & $31.5-36.6$ & 79.5 & 13.1 & $11.4-15.1$ & 75.9 & 25.7 & $23.4-28.2$ & 11.2 & $9.6-13.0$ \\
\hline Testis & 77 & 53.2 & $42.2-64.0$ & 100.0 & 15.6 & $9.1-25.3$ & 25.0 & 42.9 & $32.4-54.0$ & 18.2 & $11.1-28.2$ \\
\hline Other male genital organs & 3 & 0.0 & $0.0-56.1$ & 0.0 & 0.0 & $0.0-56.1$ & 0.0 & 0.0 & $0.0-56.1$ & 0.0 & $0.0-56.1$ \\
\hline Kidney & 218 & 46.3 & $39.8-53.0$ & 97.0 & 13.3 & $9.4-18.4$ & 82.7 & 39.0 & $32.8-45.6$ & 27.1 & $21.6-33.3$ \\
\hline Bladder and urinary tract & 710 & 77.9 & $74.7-80.8$ & 35.8 & 13.2 & $10.9-15.9$ & 70.2 & 17.3 & $14.7-20.3$ & 12.7 & $10.4-15.3$ \\
\hline Eye & 20 & 0.0 & $0.0-16.1$ & 0.0 & 0.0 & $0.0-16.1$ & 0.0 & 5.0 & $0.9-23.6$ & 20.0 & $8.1-41.6$ \\
\hline Thyroid gland & 114 & 37.7 & $29.4-46.9$ & 97.7 & 15.8 & $10.2-23.6$ & 83.3 & 21.1 & $14.6-29.4$ & 3.5 & $1.4-8.7$ \\
\hline Adrenal gland & 7 & 42.9 & $15.8-74.9$ & 66.6 & 28.6 & $8.2-64.1$ & 50.0 & 57.1 & $25.0-84.2$ & 42.9 & $15.8-75.0$ \\
\hline Melanoma & 286 & 65.0 & $58.6-70.8$ & 100.0 & 24.8 & $19.7-30.7$ & 91.4 & 32.1 & $26.4-38.3$ & 12.4 & $8.8-17.2$ \\
\hline Lymphoma & 505 & - & & & - & & - & - & & 34.9 & $30.8-39.1$ \\
\hline Myeloma & 131 & - & & & - & & - & - & & 26.0 & $19.2-34.1$ \\
\hline TOTAL & 3514 & 48,6 & $47.5-49.6$ & 70.6 & 36,5 & $35.6-37.5$ & 70.9 & 40,6 & $39.6-41.6$ & 37.9 & $36.9-38.8$ \\
\hline
\end{tabular}

$\mathrm{a}_{\%} \mathrm{~T}$ or $\mathrm{N}$ pathological

SEER registries [6-10, 13], but a lower completeness in young adults and elderly. We believe that there are different explanations for both age groups. In patients under 40 years old, perhaps it is due to a predominance of cancers that cannot be staged with TNM, as it happen with childhood cases. On the other hand, in patients over 80, we found lower $\mathrm{T}, \mathrm{N}$ and $\mathrm{M}$, but a similar percentage of stage grouping, probably due to less aggressive treatments in elderly people $[14,15]$. Finally, as expected, considerably less $\mathrm{T}, \mathrm{N}, \mathrm{M}$ and stage grouping data have been found for patients diagnosed in private clinics. This is related to the absence or the inaccessibility of clinical records in these centres. Improvements in this area would be beneficial. 
Table 3 Completeness of TNM \& stage by sex, age and type of hospital in Mallorca Cancer Registry (2006-2008) ${ }^{a}$

\begin{tabular}{|c|c|c|c|c|c|c|c|c|c|c|}
\hline & & Number & $T$ & & $\mathrm{~N}$ & & $M$ & & Stage & \\
\hline Variable & Categories & & $\%$ & $\mathrm{C} 195 \%$ & $\%$ & C195 \% & $\%$ & Cl95 \% & $\%$ & C195 \% \\
\hline \multirow[t]{2}{*}{ Sex } & Women & 3657 & 49.5 & $47.9-51.2$ & 42.2 & $40.6-43.8$ & 40.6 & $39.9-42.2$ & 41.1 & $39.5-42.7$ \\
\hline & Men & 5626 & 47.9 & $46.6-49.2$ & 32.9 & $31.6-34.1$ & 40.6 & $39.3-41.2$ & 35.7 & $34.5-37.0$ \\
\hline \multirow[t]{4}{*}{ Age } & $<40$ & 447 & 44.1 & $39.5-48.7$ & 32.0 & $27.8-36.4$ & 32.9 & $28.7-33.0$ & 32.9 & $28.7-37.4$ \\
\hline & $40-65$ & 3926 & 51.6 & $50.0-53.1$ & 40.8 & $39.3-42.3$ & 44.3 & $42.8-45.9$ & 41.0 & $39.4-42.5$ \\
\hline & $66-80$ & 3590 & 49.5 & $47.9-51.1$ & 36.0 & $34.4-37.5$ & 39.8 & $38.2-41.4$ & 37.2 & $32.6-35.7$ \\
\hline & $>80$ & 1320 & 38.6 & $36.0-41.2$ & 27.0 & $24.6-29.4$ & 34.2 & $31.7-36.8$ & 32.2 & $29.7-34.8$ \\
\hline \multirow[t]{2}{*}{ Type of hospital } & Public & 6889 & 54.7 & $53.5-55.9$ & 41.1 & $38.9-42.2$ & 47.4 & $46.3-48.6$ & 44.2 & $43.0-45.4$ \\
\hline & Private & 2394 & 30.8 & $29.0-32.7$ & 23.6 & $21.9-25.3$ & 20.9 & $19.3-22.6$ & 19.5 & $18.0-21.1$ \\
\hline
\end{tabular}

Percentages

Apart from completeness, the accuracy of T, N, M and stage grouping in cancer registries should also be assessed, as New Zealand Cancer Registry is doing [14]. In our case, the benchmark should be the revision of clinical records by an oncologist. It would be interesting also to compare the accuracy of T, N, M and stage grouping between automatic data collection systems, such as the DCR, and registries using manual collection such as the MCR. It has to be admitted that collection of T, N, M and stage grouping using our method involves the review of almost all clinical records, which is laborious but feasible thanks to the availability of electronic clinical records. Furthermore, a high degree of accuracy can be expected, since multiple sources are used.

The current TNM System already does include some symptoms and molecular patterns. Future editions will almost certainly include more, as some authors claim [16]. Nevertheless, in population-based cancer registries, which prioritise quality over amount of information collected, adding new variables to their dataset has to be carefully considered because each new variable can dramatically increase the workload involved. Obtaining feedback from oncologists and other clinicians would be appropriate in this regard.

\section{Conclusions}

In conclusion, collection of T, N, M and stage grouping data in population-based cancer registries is feasible and desirable, as stage is the main prognostic factor in many cancers. An international agreement on recommended $\mathrm{T}, \mathrm{N}$ and $\mathrm{M}$ assumptions for missing data is proposed in addition to another for the eventual inclusion of new variables for stage grouping.

\section{Abbreviations}

CNS: Central Nervous System; DCO: Death Certificate Only case: Case indentified only through the death certificate; DCR: Danish Cancer Registry; ICD-O: International Classification of Diseases for Oncology; MCR: Mallorca Cancer Registry; M: Metastasis; N: Local lymph node involvement; SEER: Surveillance, Epidemiology and End Results Program (US); T: Primary tumour growth; TNM: Tumour Node Metastasis System; UICC: International Union Against Cancer.

\section{Competing interests}

The authors report no conflicts of interest in this work, which has received no specific grant from any funding agency.

\section{Authors' contributions}

$M R$ and PF designed the study. MR, PF, MZ, JA and MD contributed to data collection and their quality control. MR and PF did the analysis. MR wrote the manuscript. All authors have read and approved the manuscript.

\section{Acknowledgments}

We appreciate the critical reading of the manuscript done by Carme Font, Joaquim Puxam, Magdalena Esteva, Joan Llobera and Magdalena Medinas. We have received no extra funds for this project.

\section{Author details}

${ }^{1}$ Mallorca Cancer Registry, Public Health Department, Hospital Psiquiàtric 40, 07110 Palma, Balearic Islands, Spain. ${ }^{2}$ Hospital Son Espases Tumour Registry, Balearic Islands Health Service, Palma, Spain. ${ }^{3}$ Hospital Manacor Tumour Registry, Balearic Islands Health Service, Manacor, Spain.

Received: 20 January 2014 Accepted: 26 October 2015

Published online: 04 November 2015

\section{References}

1. Sobin LH, Gospodarowicz MK, Wittekind C. TNM Classification of Malignant Tumors, International Union Against Cancer. 7th ed. Oxford: Wiley-Blackwell; 2010.

2. Curado MP, Edwards B, Shin HR, Storm H, Ferlay J, Heanue M, et al. Cancer Incidence in Five Continents, IARC Scientific Publications, No 160, vol. IX Lyon: IARC; 2007.

3. De Cancela Camargo M, Chapuis F, Curado MP. Abstracting stage in population-based cancer registries: the example of oral cavity and oropharynx cancers. Cancer Epidemiol. 2010;34(4):501-6.

4. Sogaard M, Olsen M. Quality of cancer registry data: completeness of TNM staging and potential implications. Clin Epidemiol. 2012;4 Suppl 2:1-3.

5. Fritz A, Percy C, Jack A, Shanmugaratnam K, Sobin L, Parkin M, et al. International Classification of Diseases for Oncology (ICD-O). 3rd ed. Geneva: World Health Organisation; 2000.

6. Holland-Bill L, Froslev T, Friis S, Olsen M, Harving N, Borre M, et al. Completeness of bladder cancer staging in the Danish Cancer Registry, 2004-2009. Clin Epidemiol. 2012;4 Suppl 2:25-31.

7. Gulbech A, Schou M, Froslev T, Fris S, Garne JP, Sogaard M. Completeness of breast cancer staging in the Danish Cancer Registry, 2004-2009. Clin Epidemiol. 2012:4 Suppl 2:11-6.

8. Nguyen-Nielsen M, Froslev T, Friis S, Borre M, Harving N, Sogaard M. Completeness of prostate cancer staging in the Danish Cancer Registry, 2004-2009. Clin Epidemiol. 2012;4 Suppl 2:17-23. 
9. Froslev T, Grann AF, Olsen M, Olesen AB, Schmidt H, Friis $\mathrm{S}$, et al. Completeness of TNM cancer staging for melanoma in the Danish Cancer Registry, 2004-2009. Clin Epidemiol. 2012;4 Suppl 2:5-10.

10. Deleuran T, Sogaard M, Froslev T, Rasmussen TR, Jensen HK, Friis S, et al. Completeness of TNM staging of small-cell and non-small-cell lung cancer in the Danish Cancer Registry, 2004-2009. Clin Epidemiol. 2012;4 Suppl 2:39-44.

11. Eisermann N, Waldmann A, Katalinic A. Imputation of missing values of tumour stage in population-based cancer registration. BMC Med Res Methodol. 2011;11:129.

12. Marshall A, Altman DG, Royston P, Holder RL. Comparison of techniques for handling missing covariate data within prognostic modelling studies: a simulation study. BMC Med Res Methodol. 2010;10:7.

13. Merrill RM, Sloan A, Anderson AE, Ryker K. Unstaged cancer in the United States: a population-based study. BMC Cancer. 2011;11:402.

14. Seneviratne S, Campbell I, Scott N, Shirley R, Peni T, Lawrenson R. Accuracy and completeness of the New Zealand Cancer Registry for staging of invasive breast cancer. Cancer Epidemiol. 2014:38:638-44.

15. Esteva M, Ruiz A, Ramos M, Casamitjana M, Sánchez-Calavera MA, González-Luján L, et al. Age differences in presentation, diagnosis pathway and management of colorectal cancer. Cancer Epidemiol. 2014;38(4):346-53

16. Epstein RJ. TNM: Therapeutically Not Mandatory. Eur J Cancer. 2009;45:1111-6.

\section{Submit your next manuscript to BioMed Central and take full advantage of:}

- Convenient online submission

- Thorough peer review

- No space constraints or color figure charges

- Immediate publication on acceptance

- Inclusion in PubMed, CAS, Scopus and Google Scholar

- Research which is freely available for redistribution 